\title{
BMJ Open Death, injury and disability from kinetic impact projectiles in crowd- control settings: a systematic review
}

\author{
Rohini J Haar, ${ }^{1}$ Vincent lacopino, ${ }^{2}$ Nikhil Ranadive, ${ }^{3}$ Madhavi Dandu, ${ }^{4}$ \\ Sheri D Weiser ${ }^{5}$
}

To cite: Haar RJ, lacopino V, Ranadive N, et al. Death, injury and disability from kinetic impact projectiles in crowd-control settings: a systematic review. BMJ Open 2017;7:e018154. doi:10.1136/ bmjopen-2017-018154

- Prepublication history for this paper is available online. To view these files, please visit the journal online (http://dx.doi. org/10.1136/bmjopen-2017018154).

Received 8 June 2017 Revised 22 September 2017 Accepted 28 September 2017

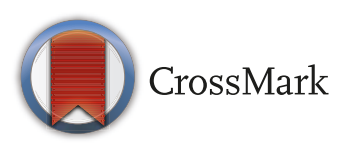

${ }^{1}$ School of Public Health, Division of Epidemiology, University of California, Berkeley, California, USA

${ }^{2}$ Physicians for Human Rights, New York, New York, USA ${ }^{3}$ Emory University School of Medicine, Atlanta, Georgia, USA ${ }^{4}$ Department of Medicine, University of California, San Francisco, California, USA ${ }^{5}$ Division of HIV, ID and Global Medicine, Department of Medicine, University of California, San Francisco, California, USA

Correspondence to Dr Rohini J Haar; rohinihaar@berkeley.edu

\begin{abstract}
Objective We conducted a systematic review of the available literature on deaths, injuries and permanent disability from rubber and plastic bullets, as well as from bean bag rounds, shot pellets and other projectiles used in arrests, protests and other contexts from 1 January 1990 until 1 June 2017.
\end{abstract}

Data sources PubMed, Scopus, JSTOR and grey literature.

Data synthesis We report on descriptive statistics as well as data on injury severity, permanent disability and death. We analysed potential risk factors for injury severity, including the site of impact, firing distance and access to medical care.

Results Of 3228 identified articles, 26 articles met inclusion criteria. These articles included injury data on 1984 people, 53 of whom died as a result of their injuries. 300 people suffered permanent disability. Deaths and permanent disability often resulted from strikes to the head and neck ( $49.1 \%$ of deaths and $82.6 \%$ of permanent disabilities). Of the 2135 injuries in those who survived their injuries, $71 \%$ were severe, injuries to the skin and to the extremities were most frequent. Anatomical site of impact, firing distance and timely access to medical care were correlated with injury severity and risk of disability. Conclusions Kinetic impact projectiles (KIPs), often called rubber or plastic bullets, are used commonly in crowd-control settings. We find that these projectiles have caused significant morbidity and mortality during the past 27 years, much of it from penetrative injuries and head, neck and torso trauma. Given their inherent inaccuracy, potential for misuse and associated health consequences of severe injury, disability and death, KIPs do not appear to be appropriate weapons for use in crowd-control settings. There is an urgent need to establish international guidelines on the use of crowd-control weapons to prevent unnecessary injuries and deaths.

\section{BACKGROUND}

In recent years, there has been significant attention to the number of popular protests challenging governments and other powerful actors. ${ }^{12}$ In many cases, police and security forces have responded in ways that fundamentally undermine freedom of peaceful assembly and often lead to escalation through

\section{Strengths and limitations of this study}

The review methodology incorporates all published and relevant information on various types of kinetic impact projectiles (KIPs) including rubber and plastic bullets and shotgun pellets.

- The review allows understanding of the range of injuries and disabilities, these weapons can cause in myriad contexts.

- The review is limited by the limited quality and number of published data on injuries secondary to KIPs.

- Meta-analysis of the data is not possible secondary to the heterogeneity of the studies.

the unnecessary and disproportionate use of force. ${ }^{3-5}$ Such use of force often involves crowd-control weapons (CCWs) that cause preventable injury, disability and death.

Kinetic impact projectiles (KIPs), commonly called rubber or plastic bullets, are CCWs that are designed to incapacitate individuals by inflicting pain or sublethal injury. Some KIPs target an individual with a single projectile, while others target a group by scattering multiple projectiles. ${ }^{6-8}$ Manufacturers produce more than 75 different types of bullets and launchers in many countries, including Brazil, China, Israel, South Africa, South Korea and the USA, ${ }^{910}$ and are marketed to military, police and private security forces throughout the world. ${ }^{11}$ Despite the widespread use of KIPs and the numerous types available, there is limited regulation of the development of these weapons and limited public information provided by manufacturers on their design and guidelines for use. ${ }^{1213}$

All projectile weapons function by transferring kinetic energy from a weapon into the body of an individual. Ballistics data indicate that denser objects and faster projectile speeds increase the force of impact. ${ }^{14}$ KIPs have a wide range of 
variables that can impact injury patterns and severity, including the material composition, shape, number, muzzle velocity (projectile speed exiting the weapon) and flight path of projectiles, the firing distance and the location of impact on the body. ${ }^{15}$ It is important to note that many KIPs have muzzle velocities equal to those of live ammunition. Most KIPs are designed with a large surface area to produce a rapid loss of speed during flight and reduce the chance of skin penetration, but this also results in unpredictable flight paths and reduced accuracy. ${ }^{16}$ Newer weapons include projectiles with a hard outer shell coating, tear gas or pepper spray that explodes on impact, and 'attenuated energy projectiles' with hollow tips to limit the risk of ricochet or penetration. ${ }^{17}$

KIPs can cause blunt and penetrative injuries, ranging from localised contusions to severe organ damage and death. ${ }^{18-20}$ While there has been much recent media attention globally on the significant dangers of misusing these weapons, ${ }^{21-28}$ efforts to provide systemic documentation on injuries is limited for a number of reasons. There are limited regulations on the development of weapons, and manufacturers are not required to keep records on injuries from their products in development, field trials or actual use, ${ }^{17}$ In most countries, there is no legal requirement for law enforcement to collect data on injuries from KIPs. ${ }^{11}$ Though police may record related deaths, these data are often not publicly available or complete. ${ }^{29}$ Similarly, military data on both international and domestic use of these weapons is confidential. There is often limited communication between the healthcare providers who treat and manage injuries and police who typically use the weapons. ${ }^{30}$ While non-governmental organisations and human rights groups may report injuries or deaths in specific incidents, they have not established surveillance mechanisms to systematically collect injury data. ${ }^{11}{ }^{31}$ In addition, most of the medical literature on KIPs is sourced in case reports and case series. ${ }^{32}$ Retrospective cohort studies and prospective studies have been conducted but have been limited to specific locations and time frames and by challenges in developing adequate studies of weapons injuries in potentially volatile and politically difficult conditions.

Given the limited knowledge of the health consequences of KIPs, we undertook a systematic review of the literature to evaluate the morbidity and mortality associated with these weapons. We assessed injury type and severity as well as potential exacerbating and mitigating factors. The present study is part of a larger effort by Physicians for Human Rights and the International Network of Civil Liberties Organizations to research the health effects of weapons commonly used in crowd-control settings and develop recommendations to avoid preventable injury, disability and death.

\begin{tabular}{ll}
\hline Table 1 Search terms & \\
\hline area round & less-lethal ballistics \\
attenuated energy projectiles & nonlethal gun \\
ballistics and injuries & nonlethal projectiles \\
baton rounds & peacekeeper bullet \\
\hline bean bag rounds & pepper ball \\
bird shot & plastic bullets \\
blunt force rounds & projectile round \\
\hline buck shot & protest \\
bullets & protest bullet \\
civil disturbance & riot \\
crowd control & riot control \\
crowd control munition & rubber ball \\
crowd control projectiles & rubber bullets \\
deaths AND protest & rubber coated bullets \\
extended range impact weapons & shotgun \\
Flash ball & sponge bullet \\
foam bullet & sponge rounds \\
foam coated bullet & Sting ball \\
injuries AND protest & wooden bullets \\
kinetic impact projectiles & \\
\hline
\end{tabular}

\section{METHODS}

\section{Search strategy}

We conducted a systematic review in accordance with the Preferred Reporting Items for Systematic Reviews and Meta-Analyses guidelines. ${ }^{33}$ We searched JSTOR, PubMed and Scopus using search terms cross-referenced with the MeSH database without any language restrictions. We included varied terminology for 'rubber bullets,' 'plastic bullets,' 'bean bag rounds,' 'baton rounds' and other projectiles used in crowd-control and other settings around the world (see table 1).

\section{Study selection}

Given the paucity of literature on KIP injuries, we designed a broad search strategy to identify all potential literature on KIP-related injuries. We included studies that documented injuries, deaths or other health consequences of KIPs on any human participants and that were published between 1 January 1990 and 1 June 2017. In addition to civilian protestors, we included other individuals who may have had exposure to KIPs, including sports fans, police officers and prisoners. We included all contexts, including peaceful demonstrations, riots, sporting events, prison uprisings, arrests and accidental exposures, and during military or police training events. We included retrospective cohort studies and case series with more than four cases as well as experimental studies of the weapons. We excluded animal or cadaver studies, studies on human physiology and studies that did not have adequate documentation of the cause of injuries. In addition to the above, based on contacts with experts and 
a review of the literature and references lists, we identified reports, conference abstracts, posters, legal files and public letters that would fit the inclusion criteria.

We reviewed full titles and abstracts of all retrieved articles and obtained full texts of eligible articles. Authors NR and RJH read and selected full papers against the inclusion criteria. Studies with overlapping data were managed by selecting the more complete study with better documentation of injuries. We resolved any disagreements on article selection by discussion. We managed references using the bibliographic software Zotero.

\section{Data extraction}

In addition to standard demographic data, we categorised data from each article by weapon, context of use, country and study characteristics such as authors, full reference, study design, location, sample size, age range, gender of individuals, method of analysis and documentation of injuries and outcomes. For any studies where there were potentially duplicate data sets, we filtered the data to exclude any potential redundant injury or death data to ensure the most conservative estimates. To mitigate errors and ensure reliability, at least two researchers extracted data from each study. Data were managed using Stata (V.14.2) and Microsoft Excel (V.14.1.1).

We extracted the injury data from each included article based on the acuteness of the injuries and the resources required to care for those injuries. Minor injuries were classified as those that are present on physical examination but do not require professional medical care. These injuries include minor contusions, abrasions or sprains. Severe injuries are those that require professional medical management. These injuries range from lacerations that require suturing to penetrating injuries that require surgery or intensive care unit-level care. We also documented subjects with permanent disability or death as a result of the injuries. Blindness, for example, was defined to range from 'no light perception' to 6/60 vision (legal blindness). Under each category, authors also identified the organ or body system injured. We conducted a descriptive analysis of the injuries and mortality associated with different KIPs. Additionally, we recorded the number of people who died or sustained permanent disabilities from each type of weapon and from injuries to specific body systems to gain a better understanding of the range of injuries and causes of death due to KIPs. However, due to lack of consistent prevalence data on types of injuries, and significant variability in type of studies, populations and outcomes, we did not conduct meta-analyses.

We also extracted data from each article on any potential factors-such as firing range, type of bullet or launcher, issues of misuse of weapons, political factors and timely access to medical care-that may have influenced injury severity or deaths. We classified each article as poor, moderate or high quality based on the National Institutes of Health-Validated Case Series Quality Assessment Tool, ${ }^{34}$ a tool that best fit the studies that we identified and while originally designed for case series studies, is applicable to other types of studies. (Studies are organised by their calculated 'quality' rating in table 2.)

\section{RESULTS}

We reviewed 3228 citations, read 265 full text articles and identified 26 articles for inclusion in the systematic review (see figure 1). ${ }^{35-59}$

\section{Descriptive analysis of selected studies}

The 26 selected articles included 19 retrospective cohort studies, four prospective cohort studies and three case series. The number of subjects per study ranged from 5 to 612 persons (mean $80.2 \pm 125.1$ ), with the majority being young adults (mean age 23.4 years). Of the 1487 subjects for whom gender was documented, $93.8 \%$ were men. Eleven of the articles focused on protests, two on criminal arrests and one on a riot (several articles included more than one context). The remaining 14 articles did not specifically describe the context of use, or had documentation of injuries from individuals in a variety of contexts.

The selected articles were published between 1990 and 2017, and included subjects localised in six geopolitical regions worldwide (figure 2). The studies from Israel and the Occupied Palestinian Territory (OPT) most commonly assessed the use of KIPs during the first (1987-1993) and second (2000-2005) Intifadas. The South Asian articles discussed the use of KIPs in the Kashmir region and in Nepal. The selected articles discussed a heterogeneous group of munitions (figure 3), including rubber bullets, plastic bullets, baton rounds and bean bag rounds. Articles from Israel and the OPT and Turkey also discussed rubber-coated metal bullets or bullets that have a mixed composition of metal and plastic shards. Three of the articles included data on more than one type of bullet. The quality of the articles ranged from poor (3) to moderate (11) to high (10). Given the scarcity of detailed studies on KIPs, the authors felt it was important to include all the selected studies in the analysis and provide as much information as possible on how these weapons impact human health. (We provide specific information on each of the selected studies in table 2.)

\section{Analysis of injury data}

These 26 selected studies provided data on 1984 people with injuries, permanent disabilities and deaths as a direct consequence of KIPs. We identified $300(15 \%)$ individuals who were permanently disabled and $1631(82 \%)$ who recovered after injury.

\section{Mortality}

Fifty-three people (3\%) died from their injuries. Penetrative injuries caused $56 \%$ of the deaths, while blunt injuries caused 23\% head and neck trauma accounted for 26 (50 \%) deaths, while chest and abdominal trauma accounted for 15 (27\%) (figure 4). Only one death was from injury to an extremity: a severe knee injury that 
Table 2 Study summaries

\section{High-quality studies}

\begin{tabular}{|c|c|c|c|c|c|c|c|}
\hline Citation & Country & Study design & Projectile type & $\begin{array}{l}\text { Total people } \\
\text { injured }\end{array}$ & $\begin{array}{l}\text { People } \\
\text { that died }\end{array}$ & $\begin{array}{l}\text { People with } \\
\text { permanent } \\
\text { disability }\end{array}$ & $\begin{array}{l}\text { Total no of } \\
\text { injuries }\end{array}$ \\
\hline Balouris et $a l^{35}$ & Israel/Palestine & Retrospective & $\begin{array}{l}\text { Rubber-coated metal } \\
\text { bullet }\end{array}$ & 69 & 0 & 48 & 69 \\
\hline De Brito et $a l^{36}$ & USA & Retrospective & Bean bag round & 40 & 1 & 3 & 100 \\
\hline Dhar et $a^{58}$ & India & Prospective & Rubber bullets & 28 & 0 & 5 & 28 \\
\hline Elder $^{37}$ & Israel/Palestine & Retrospective & Rubber, plastic bullet & 11 & 0 & 10 & 11 \\
\hline Hughes et $a l^{57}$ & Northern Ireland & Retrospective & $\begin{array}{l}\text { Variation of plastic } \\
\text { bullet }\end{array}$ & 28 & 0 & 0 & 30 \\
\hline Lavy and Asleh ${ }^{38}$ & Israel/Palestine & Retrospective & $\begin{array}{l}\text { Rubber-coated metal } \\
\text { bullet }\end{array}$ & 42 & 0 & 25 & 42 \\
\hline Maguire et al ${ }^{39}$ & Northern Ireland & Retrospective & $\begin{array}{l}\text { Attenuated energy } \\
\text { projectile }\end{array}$ & 14 & 0 & 1 & 22 \\
\hline Mahajna et al ${ }^{40}$ & Israel/Palestine & Retrospective & $\begin{array}{l}\text { Rubber-coated metal } \\
\text { bullet }\end{array}$ & 152 & 3 & 6 & 202 \\
\hline Schnitzer ${ }^{41}$ & Israel/Palestine & Retrospective & Metal/PVC composite & 612 & 1 & 0 & 619 \\
\hline Sutter ${ }^{42}$ & Switzerland & Case series & Rubber bullets & 5 & 0 & 3 & 5 \\
\hline Suyama et $a l^{43}$ & USA & Retrospective & $\begin{array}{l}\text { Rubber and plastic } \\
\text { bullets, bean bag } \\
\text { rounds }\end{array}$ & 25 & 0 & 0 & 38 \\
\hline Unuvar et $a /^{59}$ & Turkey & Retrospective & Plastic bullets & 31 & 0 & 1 & 52 \\
\hline Wani et al ${ }^{44}$ & India & Prospective & $\begin{array}{l}\text { Rubber bullets, } \\
\text { shotgun pellets }\end{array}$ & 35 & 2 & 2 & 39 \\
\hline \multicolumn{8}{|c|}{ Moderate-quality studies } \\
\hline Hirshberg et $a /^{45}$ & Israel/Palestine & Retrospective & $\begin{array}{l}\text { Rubber-coated metal } \\
\text { bullet }\end{array}$ & 61 & 9 & 0 & 52 \\
\hline Hiss et $a l^{46}$ & Israel/Palestine & Case series & $\begin{array}{l}\text { Rubber-coated metal } \\
\text { bullet }\end{array}$ & 17 & 17 & $\mathrm{n} / \mathrm{a}$ & $\mathrm{n} / \mathrm{a}$ \\
\hline $\begin{array}{l}\text { Jaouni and } \\
\text { O'Shea }^{47}\end{array}$ & Israel/Palestine & Retrospective & $\begin{array}{l}\text { Rubber-coated metal } \\
\text { bullet }\end{array}$ & 154 & 0 & 154 & 154 \\
\hline Khan et $\left.a\right|^{48}$ & India & Prospective & Rubber bullets & 5 & 0 & 5 & 5 \\
\hline Mir et $a l^{49}$ & India & Prospective & Unknown & 64 & 1 & 21 & 63 \\
\hline Paret et $\left.a\right|^{50}$ & Israel/Palestine & Retrospective & Plastic bullets & 29 & 10 & 8 & 19 \\
\hline Ritchie $^{51}$ & Northern Ireland & retrospective & PVC bullet & 101 & 0 & 2 & 104 \\
\hline $\begin{array}{l}\text { Schnitzer and } \\
\text { Fitzgerald }^{52}\end{array}$ & Israel/Palestine & Case series & $\begin{array}{l}\text { Rubber-coated metal } \\
\text { bullet }\end{array}$ & 15 & 0 & 0 & 15 \\
\hline Steele et $a^{/ 63}$ & $\begin{array}{l}\text { UK, Northern } \\
\text { Ireland }\end{array}$ & Retrospective & PVC bullet & 155 & 0 & 2 & 172 \\
\hline Yellin et $\left.a\right|^{53}$ & Israel/Palestine & Retrospective & Metal/PVC composite & 26 & 2 & 0 & 43 \\
\hline \multicolumn{8}{|c|}{ Low-quality studies } \\
\hline Hubbs $^{54}$ & USA & Retrospective & $\begin{array}{l}\text { Rubber }(40 \%) \text {, plastic } \\
(35 \%) \text { other }(25 \%) \\
\text { bullets }\end{array}$ & 177 & 3 & 0 & 158 \\
\hline $\begin{array}{l}\text { Ritchie and } \\
\text { Gibbons }{ }^{55}\end{array}$ & Northern Ireland & Retrospective & Plastic bullets & 80 & 4 & 0 & 85 \\
\hline Sharma et $a l^{56}$ & Nepal & Retrospective & Unknown & 8 & 0 & 4 & 8 \\
\hline
\end{tabular}

n/a, not available; PVC, polyvinyl chloride. 


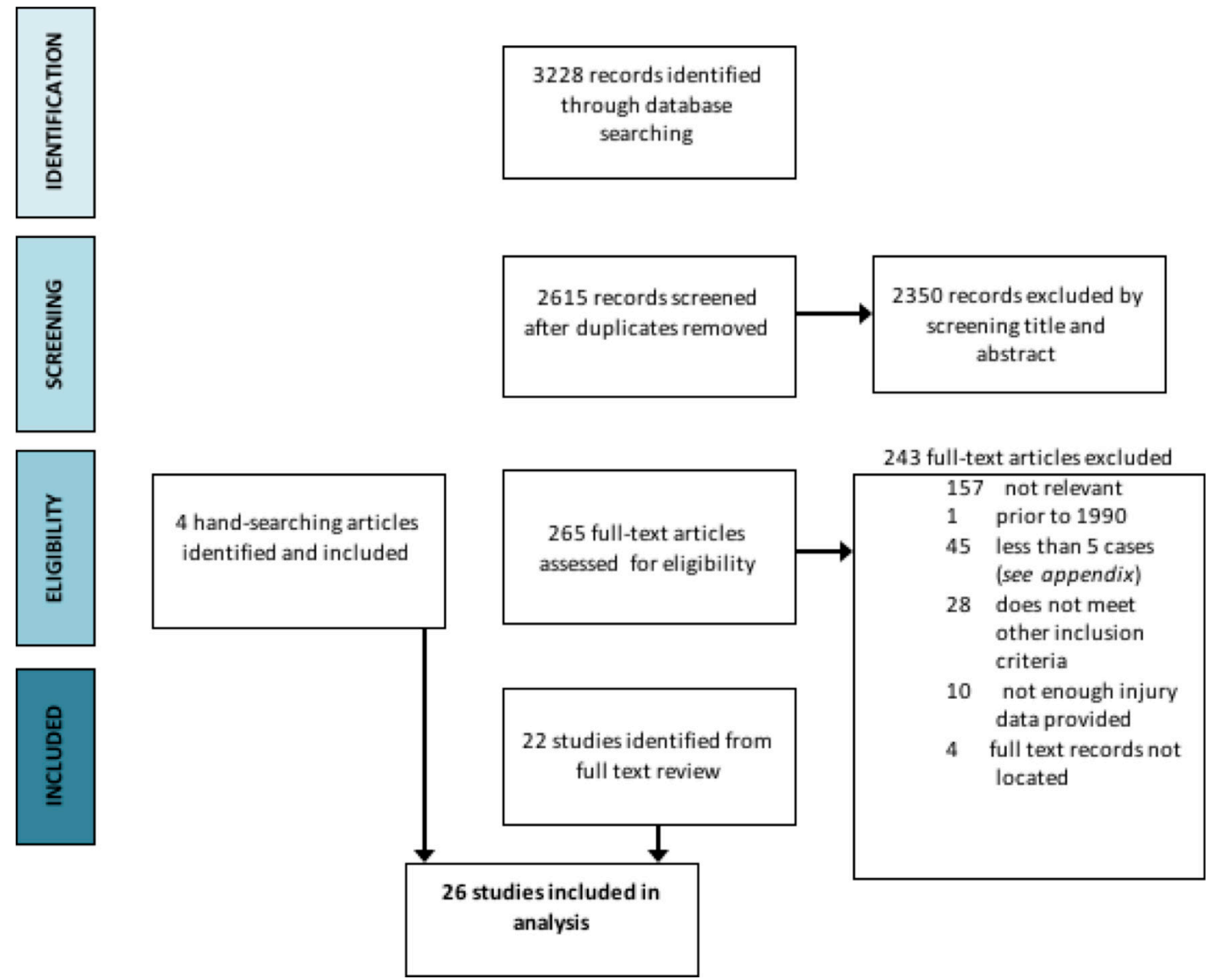

Figure 1 Results of literature search and study selection.

resulted in an air embolism to the lung, with subsequent respiratory failure. ${ }^{40}$

\section{Permanent disability}

We also identified 300 people (15.5\% of all survivors) with permanent disabilities directly caused by KIPs. The vast majority of injuries were secondary to vision loss and abdominal injuries resulting in splenectomies or colostomies. Amputation of a limb occurred in two individuals.

\section{Severe and minor injuries}

We identified 2135 injuries in the 1931 people who survived their injuries (including the 300 with permanent disabilities). Multiple bullets or contiguous organ injuries from single bullets contributed to the number of injuries.

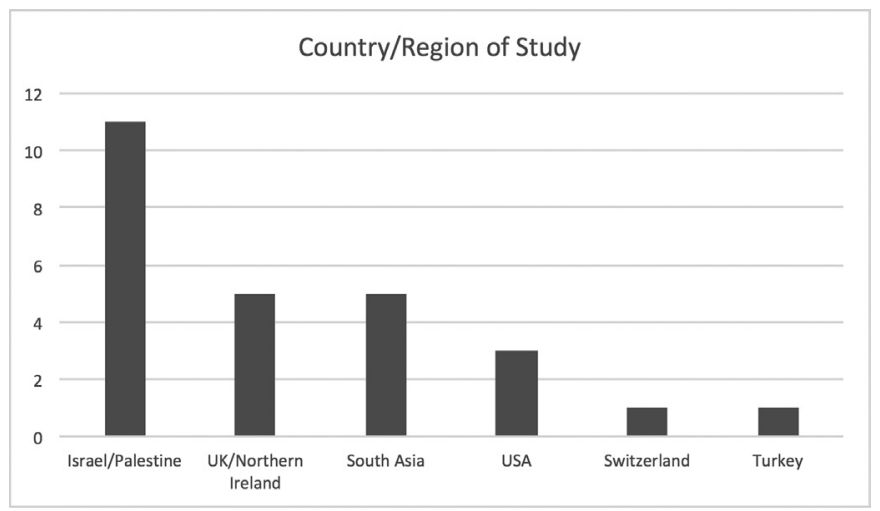

Figure 2 Regional location of the included studies.
Seventy-one per cent of these injuries were severe. Nearly all body systems were involved and injuries to the skin and to the extremities were most frequent. Almost all $(91.5 \%$, $\mathrm{n}=732$ ) head and neck, ocular, nervous, cardiovascular, pulmonary and thoracic, abdominal and urogenital injuries were severe. Skin injuries, though frequent, were often minor injuries $(76.5 \%, \mathrm{n}=636)$. Eighty-seven per cent of musculoskeletal injuries to the limbs were severe.

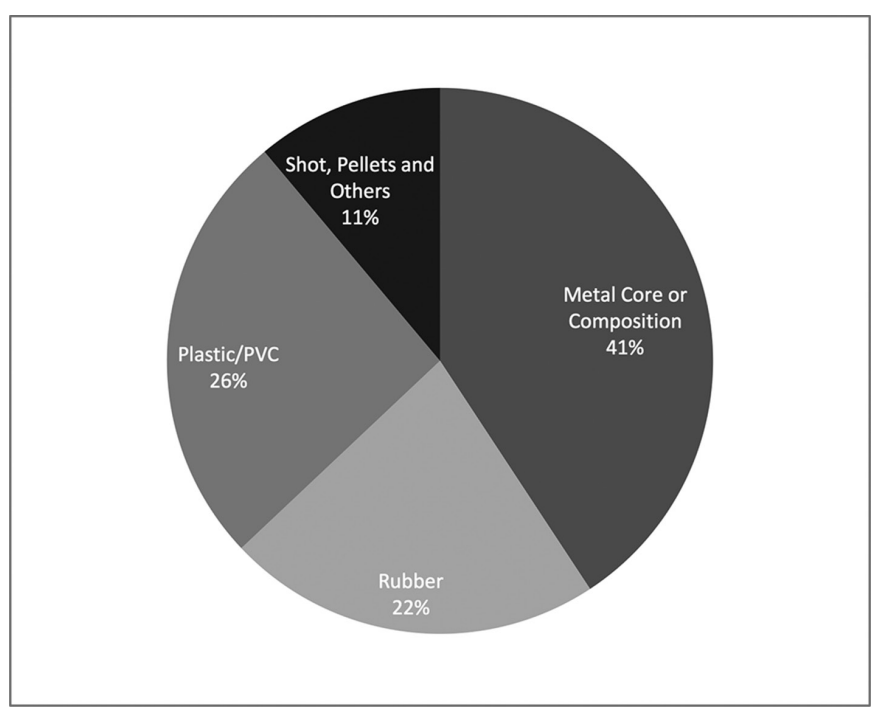

Figure 3 Types of projectiles (kinetic impact projectiles) in included studies. PVC, polyvinyl chloride. 


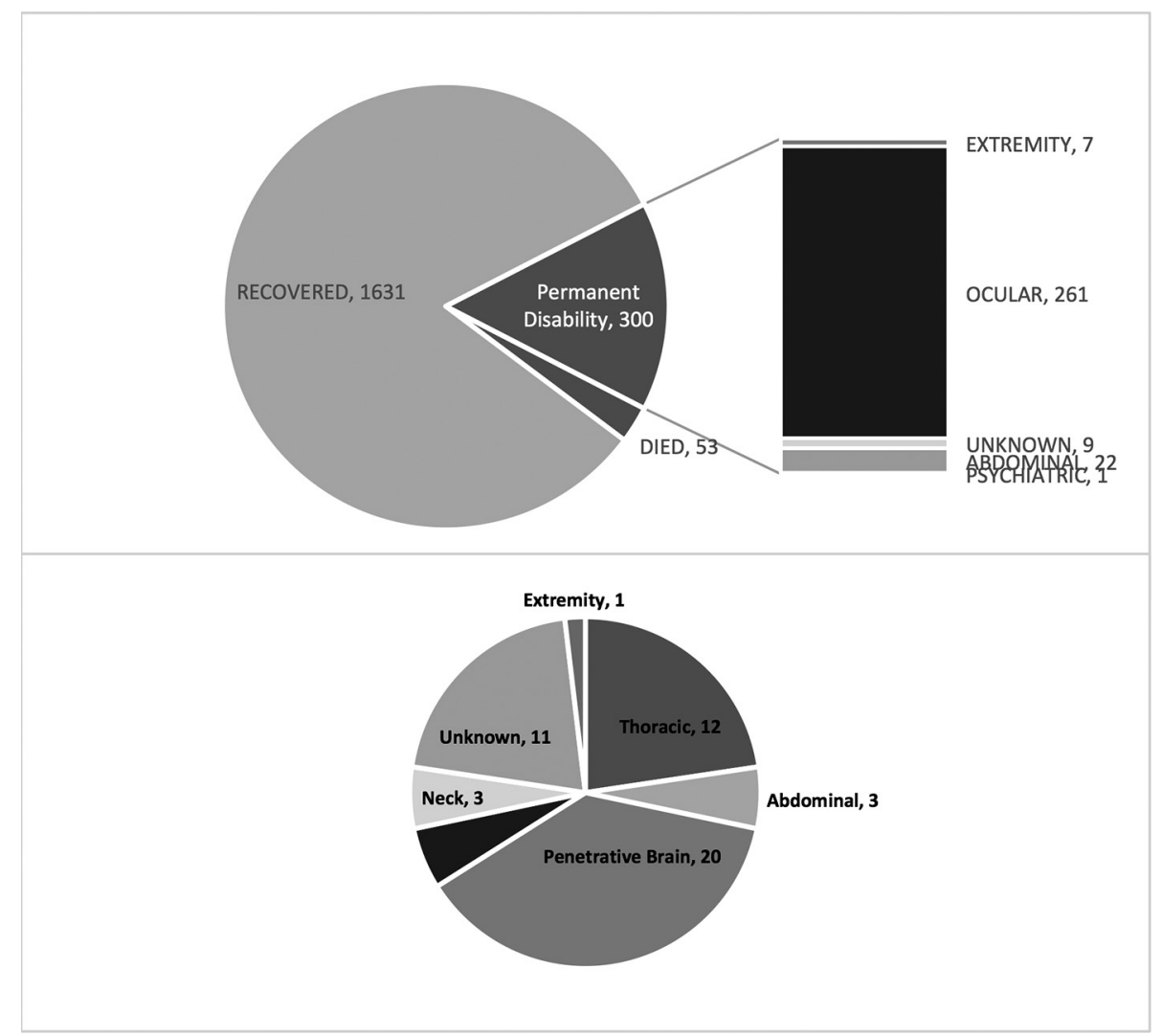

Figure 4 Health consequences documented for kinetic impact projectiles in the included studies.

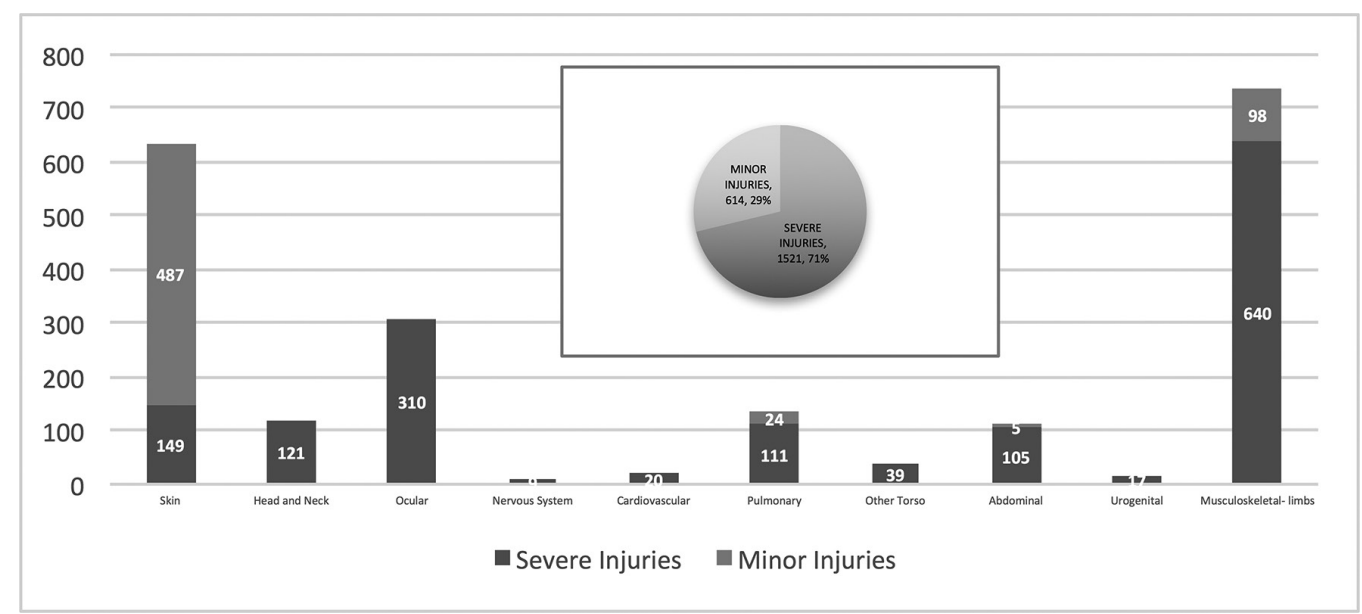

Figure 5 Severity of injuries documented for kinetic impact projectiles organised by body system.

\section{Injury severity variables}

We filtered injuries by the anatomical site of impact and bullet type to attempt to evaluate potential factors associated with severity of injury.

\section{Anatomical site}

Out of $310(84.2 \%), 261$ ocular injuries in the selected studies resulted in permanent blindness, while only 7 out of $738(0.009 \%)$ injuries to the extremities resulted in permanent disability. Out of all deaths attributable to KIPs, 26 out of $53(49.1 \%)$ were from injuries to the head or neck (figure 5).

\section{Bullet type}

Many of the injuries $(\mathrm{n}=1219)$ and permanent disabilities $(n=237)$ documented in the selected studies were from bullets that had a metal core or were otherwise composed of metal (figure 6). These bullets include rubber-coated metal bullets as well as bullets with minute metal fragments within a polyvinyl chloride matrix, and bean bag rounds in which small lead pellets are encased in a synthetic cloth bag.

Firing distance

Eight of the articles noted that the firing distance of the weapon was less than designated or directly related to the 
severity of injury. ${ }^{3638424649535458}$ Exact distance was impossible to assess in most cases, but forensics and case data suggested that the firing distances were less than those recommended by manufacturers. Several authors noted the difficulty in assessing firing distance both forensically and in real time when police work is dynamic and conditions are changing quickly. While lethal at close range, several articles also pointed out that KIPs are inherently inaccurate at longer distances. In fact, several studies reported instances in which KIP weapons unintentionally injured bystanders and non-violent demonstrators instead of the specific individuals that were targeted. ${ }^{47-49}$

\section{Access to medical care}

Seven articles noted that delays to medical care contributed to morbidity. ${ }^{35} 43-45475356$ Checkpoints, fear of arrest or retribution, limited availability of surgical or subspecialty care and political, social or economical limitations on transportation to appropriate medical centres were all noted as reasons that patients did not seek or were not afforded access to timely medical care. ${ }^{4344}$

\section{DISCUSSION}

The findings of this study indicate that KIPs have caused serious injury, disability and death. In the 26 studies selected for analysis, we identified 1984 people with injuries, 53 of whom died as a result of their injuries. Among those injured, $71 \%$ had injuries that were considered severe and 300 people suffered permanent disabilities. Permanent disabilities and severe injuries often resulted from strikes to the head and neck ( $48 \%$ of deaths and $87 \%$ of permanent disabilities). The use of KIPs in crowd-control settings is based on the premise that KIP weapons are 'less lethal.' KIPs are designed to limit the kinetic energy on impact to prevent penetrating injuries within a specific shooting range. Our findings indicate that these weapons have the potential to cause severe injuries and death.
We know that the muzzle velocity of KIPs is similar to lethal ammunition and that death, severe injuries and permanent disability from KIPs, in practice, occurs from bullets shots to vital organs at close range including the head, neck, chest and abdomen. To prevent severe injury, most protocols for the use of KIPs instruct law enforcement to use the weapons from a 'safe distance' and to aim at soft musculature of the lower limbs. Safe shooting distances are not well validated, however, and are highly variable among weapons, countries and manufacturers. ${ }^{811}$ In practice, deployment of KIPs may occur from distances much closer than deemed safe.

Although the data are limited, rubber-coated metal bullets and those with composites of metal and plastic appear to be more lethal than bullets composed of plastic or rubber alone. Though there is some evidence that newer 'attenuated energy projectiles' (with a hollow plastic tip that collapses on impact or a soft sponged tip) may mitigate some injuries from ricochet or deep penetrative injury, but these and all KIPs are prone to unpredictable trajectories.

The United Nations has established the general principles of necessity and proportionality for the use of force by law enforcement officials, but these principles do not provide specific guidance on the level of force that should be used in crowd-control settings, merely noting that the use of force against a peaceful crowd is illegal. ${ }^{601}$ In the USA, some police forces have established guidelines on the use of force and guidelines for crowd management, intervention and control. The vast majority of these guidelines do not require the use of force or CCWs. ${ }^{62} \mathrm{We}$ identified only two basic contexts in which CCWs should be used in crowd-control settings: (1) arrest of individuals engaged in unlawful behaviour, such as throwing rocks and (2) crowd dispersal in riot situations that threaten public safety. We note that while this article focuses on the injuries caused by KIPs, other CCWs such as tear gas, water cannons, acoustic weapons and electrical devices

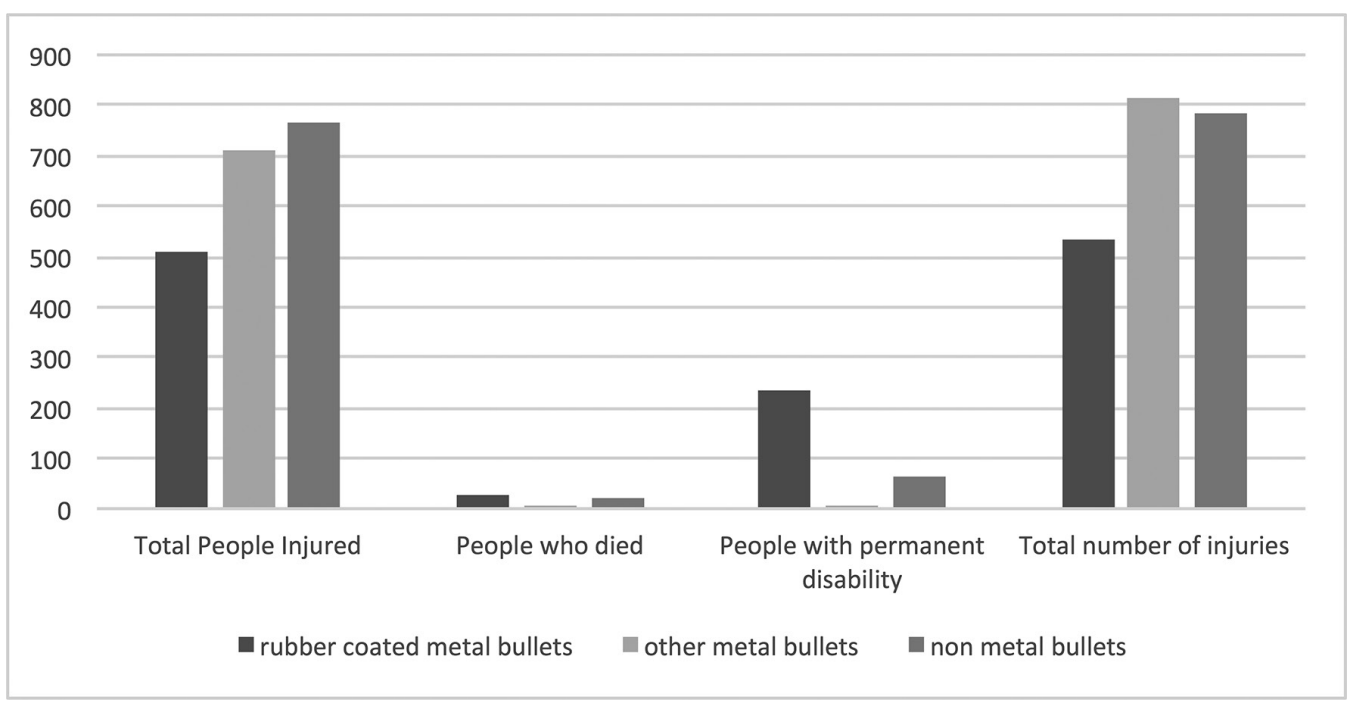

Figure 6 Health impacts of bullets with metal cores or otherwise composed of metals. 
have caused significant injury. This discussion does not in any way suggest that other weapons are safer but rather that appropriate use of force and alternatives to weapons must be considered in all contexts. Arrest of individuals requires force control in close contact with individual suspects, distances at which KIPs are not recommended and are known to result in severe injury, permanent disability and death. As weapons that cause pain and incapacitation, the effect of KIPs may also be inconsistent with the goal of crowd dispersal or the efficient and safe egress of demonstrators. Furthermore, KIPs can be inaccurate at distance and are therefore likely to cause indiscriminate injuries when used for crowd dispersal.

\section{Limitations}

In our systematic review, there were a number of important sources of potential bias. The studies included in our analysis were prone to publication bias (where the most dramatic or positive incidents are more likely to be reported), selection bias (predisposition for specific groups or people to present to specific medical facilities) and spectrum bias (variability in documentation and treatment in different clinical settings). We also note that because of the practical challenges in identifying, documenting and publishing incidents, there may be regional variations in how this information is brought to light. In addition, most of the studies we reviewed were retrospective cohort studies and there was considerable variability in quality standards, so meta-analysis was not performed. We attempted to mitigate study limitations and potential bias by developing specific inclusion and exclusion criteria, documenting reproducible injury markers and using multiple reviewers to extract data. As a result of these limitations, our findings do not allow for a precise estimate of the prevalence of specific injuries and death related to KIPs. Despite these limitations, the findings of this study are based on a rigorous analysis of the available literature and provide considerable insight into the health consequences of KIPs.

\section{CONCLUSION}

Given the inherent inaccuracy of KIPs, risk of serious injury or death and potential for deliberate misuse, our findings suggest that KIPs do not appear to be an appropriate means of force in crowd-control settings. Though the data are limited, rubber-coated metal bullets and those with metal composites may cause more injuries than other types of ammunition, and those types of bullets, in particular, should be restricted. More research is required to better understand regional differences in the usage, policy and accountability around the use of these weapons. There is an urgent need to establish international guidelines on the use of CCWs to prevent unnecessary injury, disability and death, particularly in the use of operational models that avoid the use of weapons. Our findings support the recent UN Human Rights Council resolution to develop practical recommendations for the proper management of assemblies by March 2016 in conjunction with civil society stakeholders.

Acknowledgements The authors acknowledge Widney Brown, JD; Neil Corney; George Rutherford, MD.

Contributors VI and RJH conceived of the research. RJH, NR, MD and SDW developed the study design and methodology. RJH and NR searched the scientific literature and conducted the analysis. RJH wrote the initial manuscript. All authors contributed to revisions and approved the final manuscript.

Funding Publication made possible in part by support from the Berkeley Research Impact Initiative (BRII) sponsored by the UC Berkeley Library.

Competing interests All authors have completed the ICMJE uniform disclosure form at http://www.icmje.org/coi_disclosure.pdf and declare: no support from any organization for the submitted work; no financial relationships with any organizations that might have an interest in the submitted work in the previous three years, no other relationships or activities that could appear to have influenced the submitted work.

Provenance and peer review Not commissioned; externally peer reviewed.

Data sharing statement All data will be made available via email to the corresponding author.

Open Access This is an Open Access article distributed in accordance with the Creative Commons Attribution Non Commercial (CC BY-NC 4.0) license, which permits others to distribute, remix, adapt, build upon this work non-commercially, and license their derivative works on different terms, provided the original work is properly cited and the use is non-commercial. See: http://creativecommons.org/ licenses/by-nc/4.0/

(c) Article author(s) (or their employer(s) unless otherwise stated in the text of the article) 2017. All rights reserved. No commercial use is permitted unless otherwise expressly granted.

\section{REFERENCES}

1. Global Database of Events, Language and Tone. The GDELT Project. http://gdeltproject.org/

2. Ortiz I, Burke S, Berrada M, et al. World Protests 2006-2013, IPD/FES Working Paper, 2013. http://policydialogue.org/files/ publications/World_Protests_2006-2013-Complete_and_Final_ 4282014.pdf

3. Payne-James JJ, Rivers E, Green P, et al. Trends in less-lethal use of force techniques by police services within England and Wales: 20072011. Forensic Sci Med Pathol 2014;10:50-5.

4. Alpert GP, Dunham RG. Understanding police use of force: Officers, suspects, and reciprocity: Cambridge University Press, 2004. http:// www.scopus.com/inward/record.url?eid=2-s2.0-84922918180\&partn erID $=40 \&$ md5 $=0025588 \mathrm{c} 09 \mathrm{~b} 911 \mathrm{e} 490 \mathrm{bb} 9808 \mathrm{~d} 9 \mathrm{~d} 8 \mathrm{fd} 03$.

5. Bylander J, Unrest C. Police Use Of Force, And The Public's Health. Health Aff 2015;34:1264-8.

6. Downs RL. Less lethal weapons: a technologist's perspective. Policing 2007;30:358-84.

7. Vilke GM, Chan TC. Less lethal technology: medical issues. Policing: 2007;30:341-57.

8. Hughes E, Osborne R, ed, A Guidebook for Less-Lethal Devices: Planning for, Selecting, and Implementing Technology Solutions. First. U.S. National Institute of Justice. Weapons Protective Systems Technologies Center, 2010.

9. Gobinet P. Procurement Policy: Police Use of Emerging Weapons Technology. In: States of Security. Geneva, Switzerland: Cambridge University Press, 2011:68-99. http://www.smallarmssurvey.org/ fileadmin/docs/H-Research_Notes/SAS-Research-Note-8.pdf. (accessed 3 Dec 2014).

10. Global Non-Lethal Weapons Market 2015-2019. Techinavio 2015. http://www.reportlinker.com/p01911331-summary/Global-Nonlethal-Weapons-Market.html.

11. Omega Research Foundation, Amnesty International. The Human Rights Impact of Less Lethal Weapons and Other Law Enforcement Equipment. London, UK: Amnesty International, 2015.

12. U.S. Department of Justice. Review of the Department of Justice's Use of Less Lethal Weapons. 2009 https://oig.justice.gov/reports/ plus/e0903/final.pdf.

13. Crowley M. Regulation of Riot Control Agents and Incapacitants Under the Chemical Weapons Convention. http://www. 
omegaresearchfoundation.org/assets/downloads/publications/02.pdf (accessed 3 Dec 2014).

14. Maiden N. Ballistics reviews: mechanisms of bullet wound trauma. Forensic Sci Med Pathol 2009;5:204-9.

15. Hollerman JJ, Fackler ML, Coldwell DM, et al. Gunshot wounds: 1. Bullets, ballistics, and mechanisms of injury. AJR Am J Roentgenol 1990;155:685-90.

16. Bir C, Biomechanics BI. Accidental Injury: biomechanics and prevention. . New York: Springer New York, 2015:829. 39. http://link. springer.com/chapter/.

17. Omega Research Foundation. Crowd Control Technologies: An appraisal of technologies for political control. Manchester, UK: European Parliament, Directorate General for Research, 2000. The STOA Programme. http://www.omegaresearchfoundation.org/ assets/downloads/publications/19991401a_en.pdf. (accessed 3 Dec 2014).

18. Metress EK, Metress SP. The anatomy of plastic bullet damage and crowd control. Int J Health Serv 1987;17:333-42.

19. Millar R, Rutherford WH, Johnson S, et al. Injuries caused by rubber bullets: a report on 90 patients. Br J Surg 1975;62:480-6.

20. Rocke L. Injuries caused by plastic bullets compared with those caused by rubber bullets. Lancet 1983;1:919-20.

21. The Associated Press. Spain: Police Fired Rubber Bullets at Migrants: N. Y. Times, 2014. http://www.nytimes.com/2014/02/22/ world/europe/spain-police-fired-rubber-bullets-at-migrants.html. (accessed 24 Sep 2015).

22. Cohen G. "Israeli Troops Use Rubber Bullets Against IDF Regulations.".Haaretz. 2014 http://www.haaretz.com/news/ diplomacy-defense/1.596208 (accessed 24 Sep 2015).

23. South African police fire rubber bullets at school protest: Reuters, 2015. http://www.reuters.com/article/2015/08/18/us-safrica-unrestidUSKCNOQN16020150818. (accessed 24 Sep 2015).

24. Jr TF AM, Myers AL, et al. Riots, looting in Baltimore over man's death in police custody: WAVY-TV. http://wavy.com/2015/04/27/ latest-on-police-custody-death-officers-hurt-at-mall-riot/. (accessed 24 Sep 2015).

25. Huffington Post. Ferguson Police Reportedly Shot A Female Pastor. http://www.huffingtonpost.com/2014/08/14/ferguson-pastor-shotpolice-rubber-bullet n 5678973.html. (accessed 24 Sep 2015).

26. International Business Time. Migrant crisis: Hungary approves use of army, rubber bullets and tear gas against refugees. http://www. ibtimes.co.uk/migrant-crisis-hungary-approves-use-army-rubberbullets-tear-gas-against-refugees-1520596 (accessed 24 Sep 2015).

27. Turkish police use tear gas, water cannon to disperse protest in Ankara - daily. BBC Monit Eur - Polit Supplied BBC Worldw Monit, 2013.

28. Venezuelan opposition march broken up with tear gas - daily. $B B C$ SUTm WORLD BROADCAST, 2009.

29. U.S. Department of Justice, Office of Justice Programs. National Institute of Justice. Police Use of Force, Tasers and Other LessLethal Weapons. Washington, D.C: U.S. Department of Justice, Office of Justice Programs. National Institute of Justice, 2011. https://www.ncjrs.gov/pdffiles1/nij/232215.pdf.

30. Nolan B, Ackery A. Collaborating With Police in the Emergency Department While Maintaining Patient Confidentiality: How Can We Improve? CJEM 2015;17:437-42.

31. Atkinson H, Sollom R. Weaponizing Tear Gas: Bahrain's Unprecedented Use of Toxic Chemical Agents Against Civilians. Boston, MA: Physicians for Human Rights, 2012. https://s3. amazonaws.com/PHR_Reports/Bahrain-TearGas-Aug2012-small. pdf. (accessed 3 Dec 2014).

32. Vilke GM, Chan TC. Less lethal technology: medical issues. Polic Int $J$ Police Strateg Manag 2007;30:341-57.

33. Moher D, Liberati A, Tetzlaff J, et al. Preferred reporting items for systematic reviews and meta-analyses: the PRISMA statement. PLoS Med 2009;6:e1000097.

34. NIH-National Heart, Lung, and Blood Institute. Quality assessment tool for case series studies. 2014 http://www.nhlbi.nih.gov/healthpro/guidelines/in-develop/cardiovascular-risk-reduction/tools/case series (accessed 18 Apr 2015).

35. Balouris CA. Rubber and plastic bullet eye injuries in Palestine. Lancet 1990;335:415.
36. de Brito $\mathrm{D}$, Challoner KR, Sehgal $\mathrm{A}$, et al. The injury pattern of a new law enforcement weapon: the police bean bag. Ann Emerg Med 2001;38:383-90.

37. Elder MJ. Penetrating eye injuries in children of the West Bank and Gaza strip. Eye 1993;7:429-32.

38. Lavy T, Asleh SA. Ocular rubber bullet injuries. Eye 2003;17:821-4.

39. Maguire K, Hughes DM, Fitzpatrick MS, et al. Injuries caused by the attenuated energy projectile: the latest less lethal option. Emerg Med $J$ 2007;24:103-5.

40. Mahajna A, Aboud N, Harbaji I, et al. Blunt and penetrating injuries caused by rubber bullets during the Israeli-Arab conflict in a retrospective study. The Lancet 2000;2002:1795-800.

41. Schnitzker JJ. Gunshot injuries with plastic bullets treated in a small community hospital in the gaza strip. Physicians Soc Responsib $Q$ 1992;2:25.

42. Sutter FK. Ocular injuries caused by plastic bullet shotguns in Switzerland. Injury 2004;35:963-7.

43. Suyama J, Panagos PD, Sztajnkrycer MD, et al. Injury patterns related to use of less-lethal weapons during a period of civil unrest. J Emerg Med 2003;25:219-27.

44. Wani ML, Ahangar AG, Ganie FA, et al. Pattern, presentation and management of vascular injuries due to pellets and rubber bullets in a conflict zone. J Emerg Trauma Shock 2013;6:155-8.

45. Hirshberg A, Or J, Stein M, et al. Transaxial gunshot injuries. J Trauma 1996:41:460-1.

46. Hiss J, Hellman FN, Kahana T. Rubber and plastic ammunition lethal injuries: the Israeli experience. Med Sci Law 1997;37:139-44.

47. Jaouni ZM, O'Shea JG. Surgical management of ophthalmic trauma due to the Palestinian Intifada. Eye 1997;11:392-7.

48. Khan S, Maqbool A, Abdullah N, et al. Pattern of ocular injuries in stone pelters in Kashmir valley. Saudi J Ophthalmol 2012;26:327-30.

49. Mir M, Malik U, Buch M, et al. Is Use Of Rubber Bullets Justified? Internet J Surg 2013;29 https://ispub.com/IJS/29/1/14477

50. Paret G, Dekel B, Yellin A, et al. Pediatric craniocerebral wounds from plastic bullets: prognostic implications, course, and outcome. J Trauma 1996;41:859-63.

51. Ritchie AJ. Plastic bullets: significant risk of serious injury above the diaphragm. Injury 1992;23:265-6.

52. Schnitzer JJ, Fitzgerald D. Peripheral vascular injuries from plastic bullets in children. Surg Gynecol Obstet 1993;176:172-4.

53. Yellin A, Golan M, Klein E, et al. Penetrating thoracic wounds caused by plastic bullets. J Thorac Cardiovasc Surg 1992;103:381-5.

54. Hubbs K. Less-lethal munitions as extended-range impact weapons. 1997; 37:42.

55. Ritchie AJ, Gibbons JR. Life threatening injuries to the chest caused by plastic bullets. BMJ 1990;301:1027.

56. Sharma AK, Shah DN, Shrestha JK, et al. Ocular injuries in the people's uprising of April 2006 in Kathmandu, Nepal. Nepal $J$ Ophthalmol 2014;6:71-9.

57. Hughes D, Maguire K, Dunn F, et al. Plastic baton round injuries. Emerg Med J 2005;22:111-2.

58. Dhar SA, Dar TA, Wani SA, et al. Pattern of rubber bullet injuries in the lower limbs: a report from Kashmir. Chin J Traumatol 2016;19:129-33.

59. Unuvar U, Yilmaz D, Ozyildirim I, et al. Usage of Riot Control Agents and other methods resulting in physical and psychological injuries sustained during civil unrest in Turkey in 2013. J Forensic Leg Med 2017; 45:47-52.

60. United Nations Congress on the Prevention of Crime and the Treatment of Offenders. Basic Principles on the Use of Force and Firearms by Law Enforcement Officials. 1990 http://www.ohchr.org/ Documents/Professionallnterest/firearms.pdf (accessed 5 Dec 2014).

61. General Assembly. Code of Conduct for Law Enforcement Officials. 1979 http://www.ohchr.org/EN/Professionallnterest/Pages/LawEnfor cementOfficials.aspx (accessed 5 Dec 2014).

62. Cappitelli P. POST Guidelines: Crowd management, intervention, and control. Sacramento, CA: Commission on Peace Officer Standards and Training, 2012.

63. Steele JA, McBride SJ, Kelly J, et al. Plastic bullet injuries in Northern Ireland: experiences during a week of civil disturbance. $J$ Trauma 1999;46:711-4. 